\title{
Anna K. Raggl* \\ Determinants of Total Factor Productivity in the Middle East and North Africa
}

DOI 10.1515/rmeef-2014-0017

Abstract: A decomposition of output growth rates of Middle Eastern and North African countries shows that the contributions of human capital-augmented labor and physical capital to output growth are comparably small and stable over time and that in most countries a considerable share of output growth is attributed to growth in total factor productivity. This paper empirically assesses the determinants of total factor productivity in the Middle East and North Africa region between 1980 and 2009. The findings suggest that human capital is not only an input factor of production but also a quantity that changes the efficiency by which existing input factors are used. Domestic innovations appear to be efficient only if a certain level of educational attainment is reached by a country. In addition, human capital contributes to the ability of efficient adoption of technology from abroad and allows a faster catch-up with technological leaders. Globalization, in combination with a (comparably low) threshold endowment of human capital, is estimated to increase total factor productivity in Middle Eastern and North African countries.

Keywords: total factor productivity, technological progress, human capital, technology adoption, Middle East and North Africa

\section{Introduction}

The results of a growth accounting exercise for the Middle East and North Africa (MENA) region show limited and rather stable contributions of physical capital and human capital-augmented labor to output growth between 1980 and 2009. In most countries of the region, a considerable share of output growth is attributed to growth in the Solow residual, or total factor productivity (TFP). Often referred to as productivity or technological progress, this residual remains unexplained in the accounting exercise and summarizes influential factors of output growth that cannot be accounted for by physical or human capital

*Corresponding author: Anna K. Raggl, Research Institute for Human Capital and Development, Wittgenstein Centre for Demography and Global Human Capital, Vienna University of Economics and Business, Vienna, Austria, E-mail: anna.raggl@wu.ac.at 
or labor. In order to understand the drivers of output growth rates, it is necessary to learn about factors that contribute to a more productive usage of inputs. This work is an attempt to empirically assess the determinants of technological progress in the countries of the MENA region.

There is a large literature that estimates the determinants of output growth, assuming implicitly that the variables used in the empirical setting are input factors of production. As pointed out by Miller and Upadhyay (2000) or Danquah, Moral-Benito, and Ouattara (2014), it is likely, however, that some of these variables change the way in which input factors are used, and thus their impact on output growth is only an indirect one, working via the channel of productivity. Estimating the determinants of TFP therefore constitutes an important addition to the classical empirical work on economic growth.

Although it is commonly acknowledged that technological progress is crucial for the economic development of countries, the empirical literature on the determinants of TFP is limited. Some studies assess the relationship between technological progress and human capital and the openness to trade. Using data on a cross section of 93 countries, Edwards (1998) links trade policies to long-term TFP growth and finds that more open countries tend to exhibit higher TFP growth. The results are robust to various measures of openness to trade and to different econometric specifications. This analysis is expanded by Miller and Upadhyay (2000) who add a time dimension to the data and explicitly highlight the role played by human capital. Their findings confirm the positive relation between openness and TFP. Human capital formation is found to significantly increase TFP in middle-income countries, while in low-income countries the impact of human capital on TFP is linked to that countries degree of openness. Vandenbussche, Aghion, and Meghir (2006) conclude from both a theoretical analysis and an empirical application involving 19 OECD economies that in countries which are relatively close to the technological frontier, high-skilled labor enhances TFP growth through technological innovations (see also Benhabib and Spiegel 1994). Research and development (R\&D) is another factor that has been shown to contribute to TFP growth. It does so not only by enhancing a country's ability for innovation by adopting new technologies but also to effectively adopt them from abroad (Griffith, Redding, and Van Reenen 2004; Kneller and Stevens 2006; Mc Morrow, Röger, and Turrini 2010)). Using econometric techniques designed to handle model uncertainty and a large array of potential explanatory variables, Danquah, Moral-Benito, and Ouattara (2014) address the question of the most relevant driver of TFP and find that besides openness to trade also countryspecific fixed effects importantly shape technological progress.

Although in some empirical applications distinctions have been made with respect to the income level of countries, heterogeneous effects across countries 
have received little attention. To the best of our knowledge, no empirical study exists that allows for regional heterogeneities, and for that reason a regionspecific analysis is particularly informative when assessing the drivers of productivity growth in the MENA region.

The TFP estimates used in the analysis are based on a standard growth accounting framework in which growth rates in gross domestic product (GDP) are decomposed into contributions from observable input factors of production and a residual term. This approach follows closely previous studies that investigate the components of economic growth (see for example Bosworth and Collins 2003, 2007; Baier, Dwyer, and Tamura 2006). Relying on a Cobb-Douglas production function that contains, in addition to physical capital and labor, also human capital as an input factor of production, the residual growth rate that is not explained by changes in production factors is used as an estimate of TFP.

In the literature the framework developed by Benhabib and Spiegel (1994) is commonly used as an underlying model for the specifications estimated in the empirical part of this paper. Human capital is seen as the main driver for technological progress, as educational attainment in the labor force promotes domestic innovations on the one hand, and the adoption of foreign technologies on the other hand. The empirical results of the application of this model to the MENA region support these assumptions. The general findings can be summarized as follows. The level of human capital alone does not show significant impacts on TFP. Only when allowing for a nonlinear relationship of TFP and educational attainment, we find that after a certain threshold level of education is reached, TFP significantly increases with improvements in the human capital stock. Interpreting this result in the spirit of Benhabib and Spiegel (1994) leads to the conclusion that only for countries with an already high level of human capital, domestic innovations are efficient and an impact factor for productivity. Among the countries included in our sample, the United Arab Emirates, Jordan and Bahrain classify for effective domestic innovation according to our model. ${ }^{1}$ The Maghreb region shows the lowest average levels of educational attainment and thus domestic innovations in the region appear not to be important determinants of TFP. Furthermore, we test whether the effect of education depends on the development level of each country. The results clearly show evidence for catch-up effects, and countries with low development levels can benefit from education to a greater extent.

According to the literature, the openness and outward orientation of a country is an important determinant of TFP (Miller and Upadhyay 2000).

1 Education levels in Egypt and Saudi Arabia are very close to the threshold and both countries are also among the countries in which domestic innovations could contribute to TFP. 
Including an index of the extent of globalization does not show significant contributions of that variable. When interacting it with education, it turns out that after reaching a certain (albeit for the region comparatively low) level of human capital, higher globalization can lead to increases in TFP.

Finally, we investigate the correlation between political, institutional, business environment-related and infrastructure-related variables and TFP growth rates. Data restrictions make it impossible to include these potentially very important factors in the regression analysis, but in order to see whether correlations exist simple scatter plots are used. The graphs show that countries characterized by high (post-2000) TFP growth rates are those with a comparatively high quality of institutions and a relatively stable political environment. In addition, high TFP growth rates are associated with a favorable business environment, a large share of technicians and researchers working in research and development as well as a high-quality infrastructure.

The following section discusses the construction of total factor productivity based on a decomposition of output growth rates. Section 3 summarizes the methodological approach and discusses in detail the results of the empirical estimation. Section 4 relates TFP growth rates to other potential covariates in a descriptive, non-causal way, and Section 5 concludes.

\section{Growth Decomposition}

\subsection{Methodology}

The method of growth accounting is built on Solow (1956), and an aggregate production function is used to decompose the growth rate of output into its components: a weighted average of the growth rates of the factor inputs and an remainder term - the Solow residual, which is commonly referred to as total factor productivity (TFP) and captures technological progress and other components of GDP growth that cannot be attributed to labor, human and physical capital.

The starting point is a Cobb-Douglas production function with constant returns to scale

$$
Y_{t}=A_{t} K_{t}^{\alpha}\left(L_{t} H_{t}\right)^{1-\alpha}
$$

where $Y_{t}$ is real GDP at time t, $A_{t}$ is total factor productivity, $K_{t}$ is the real capital stock, $L_{t}$ is total employment, and $H_{t}$ is an index of human capital. $L_{t} H_{t}$ is therefore taking into account the education of the employed labor force, by weighting employment with a measure of human capital. 
In particular, the skill-adjusted employment variable, $L_{t} H_{t}$, is generated using

$$
H_{t}=\exp \left[\phi s_{t}\right]
$$

where $\phi$ are average returns to education and $s_{t}$ are mean years of education of the working-age population.

The real capital stock $K_{t}$ is computed by first approximating the initial capital stock, and second employing the perpetual inventory method. A more detailed description of the construction of the human as well as physical capital variable can be found in the Appendix.

Taking the natural logarithm of the production function given in eq. [1] results in

$$
\ln Y_{t}=\ln A_{t}+\alpha \ln K_{t}+(1-\alpha) \ln \left(L_{t} H_{t}\right)
$$

and differentiating with respect to time $t$ yields

$$
\hat{y}_{t}=\hat{a}_{t}+\alpha \hat{k}_{t}+(1-\alpha)\left(\hat{l}_{t}+\hat{h}_{t}\right)
$$

where $\hat{y}_{t}, \hat{a}_{t}, \hat{k}_{t}, \hat{l}_{t}$ and $\hat{h}_{t}$ denote growth rates of real output, productivity, capital stock, employment, and the human capital index, respectively. $\alpha$ and $(1-\alpha)$ are factor shares in total income. ${ }^{2}$

Given real GDP, the capital stock, the labor force, and the human capital of an economy, one can determine the contributions of the production factors to output growth. The remaining Solow residual is generally attributed to the technology/productivity of a country. Determining the factors that cause TFP to change over time is the main focus of the following analysis.

\subsection{Data and Results}

The main data source for the growth decomposition is the World Bank's World Development Indicator (WDI) database, which provides data on GDP, employment, and investment. For data on educational attainment, we use the Barro and Lee (2013) dataset. Table 1 shows the average growth rates of GDP, physical capital and human capital-augmented employment as well as average growth rates of TFP for the 12 MENA countries under consideration. Tables $1-3$ in the

2 For the core analysis, a capital share in income $(\alpha)$ of 0.35 is assumed. As a robustness check, the capital share is estimated econometrically. No significant deviation from the assumed 0.35 is found. Please refer to Section 3.3 for details. 
Table 1: Average growth rates of GDP, physical capital, human capital, and TFP.

\begin{tabular}{|c|c|c|c|c|c|}
\hline Country & Decade & $\hat{y}$ & $\hat{k}$ & $\hat{\boldsymbol{l}+\hat{h}}$ & $\bar{a}$ \\
\hline \multicolumn{6}{|l|}{ GCC } \\
\hline Kuwait & $1980-89$ & 0.0054 & 0.0289 & 0.0727 & -0.0519 \\
\hline Kuwait & 1990-99 & 0.0207 & 0.0263 & 0.0140 & 0.0024 \\
\hline Kuwait & 2000-09 & 0.0667 & 0.0436 & 0.0345 & 0.0274 \\
\hline Bahrain & $1980-89$ & 0.0123 & 0.0658 & 0.0512 & -0.0440 \\
\hline Bahrain & 1990-99 & 0.0531 & 0.0337 & 0.0452 & 0.0119 \\
\hline Bahrain & 2000-09 & 0.0615 & 0.0469 & 0.0754 & 0.0214 \\
\hline Saudi Arabia & $1980-89$ & -0.0161 & 0.0016 & 0.0788 & -0.0678 \\
\hline Saudi Arabia & 1990-99 & 0.0301 & 0.0146 & 0.0350 & 0.0022 \\
\hline Saudi Arabia & 2000-09 & 0.0327 & 0.0092 & 0.0530 & -0.0049 \\
\hline UAE & 1990-99 & 0.0533 & 0.0140 & 0.0764 & 0.0064 \\
\hline UAE & $2000-09$ & 0.0560 & 0.0206 & 0.1120 & -0.0240 \\
\hline \multicolumn{6}{|l|}{ Mashreq } \\
\hline Egypt & $1980-89$ & 0.0530 & 0.0799 & 0.0330 & 0.0036 \\
\hline Egypt & 1990-99 & 0.0423 & 0.0264 & 0.0297 & 0.0138 \\
\hline Egypt & 2000-09 & 0.0499 & 0.0390 & 0.0312 & 0.0159 \\
\hline Jordan & $1980-89$ & 0.0208 & 0.0657 & 0.0536 & -0.0370 \\
\hline Jordan & 1990-99 & 0.0469 & 0.0409 & 0.0757 & -0.0166 \\
\hline Jordan & 2000-09 & 0.0605 & 0.0300 & 0.0329 & 0.0285 \\
\hline Syria & $1980-89$ & 0.0159 & 0.0149 & 0.0485 & -0.0209 \\
\hline Syria & 1990-99 & 0.0542 & 0.0115 & 0.0421 & 0.0228 \\
\hline Syria & 2000-09 & 0.0459 & 0.0191 & 0.0321 & 0.0184 \\
\hline Yemen & 1990-99 & 0.0551 & 0.0403 & 0.0554 & 0.0040 \\
\hline Yemen & 2000-09 & 0.0387 & 0.0394 & 0.0492 & -0.0071 \\
\hline Djibouti & 1990-99 & -0.0205 & -0.0155 & 0.0429 & -0.0418 \\
\hline Djibouti & 2000-09 & 0.0352 & 0.0113 & 0.0398 & -0.0023 \\
\hline \multicolumn{6}{|l|}{ Maghreb } \\
\hline Tunisia & $1980-89$ & 0.0304 & 0.0470 & 0.0323 & -0.0070 \\
\hline Tunisia & 1990-99 & 0.0494 & 0.0378 & 0.0365 & 0.0124 \\
\hline Tunisia & 2000-09 & 0.0455 & 0.0353 & 0.0268 & 0.0157 \\
\hline Morocco & $1980-89$ & 0.0376 & 0.0418 & 0.0351 & 0.0001 \\
\hline Morocco & 1990-99 & 0.0257 & 0.0355 & 0.0337 & -0.0086 \\
\hline Morocco & 2000-09 & 0.0463 & 0.0503 & 0.0209 & 0.0151 \\
\hline Algeria & $1980-89$ & 0.0294 & 0.0514 & 0.0527 & -0.0228 \\
\hline Algeria & 1990-99 & 0.0153 & 0.0139 & 0.0551 & -0.0254 \\
\hline Algeria & 2000-09 & 0.0354 & 0.0277 & 0.0390 & 0.0004 \\
\hline
\end{tabular}

Appendix illustrate yearly contributions of factor inputs and TFP to GDP growth. The decomposition shows that as the contributions of factor inputs were relatively stable over time, the considerable fluctuations of GDP growth rates are mainly attributed to TFP. 
This result holds for Gulf Cooperation Council (GCC) countries, as well as for Mashreq and Maghreb countries. Physical and human capital and employment appear to have limited power in explaining output growth, and the better part of variation in output growth remains unexplained and is summarized in the residual TFP. In order to shed light on the determinants of TFP, a panel regression framework is employed that links the countries' ability to adopt technology from abroad, their potential for domestic innovation as well as their openness to changes in TFP.

\section{Determinants of Technological Progress}

\subsection{Theoretical Background and Econometric Specifications}

As specified in eq. [1], a country's output growth depends on the growth rates of physical capital, human capital, and the labor force. After accounting for these inputs of production, the remaining residual (Solow residual, TFP)

$$
A_{t}=\frac{Y_{t}}{K_{t}^{\alpha}\left(L_{t} H_{t}\right)^{1-\alpha}}
$$

can be (partially) attributed to the level of technology of the country. The growth decomposition shows that in the MENA region this residual accounts for a considerable part of GDP growth rates (Table 1 and Figures 1-3), and changes in the growth rate of output are mainly attributed to the growth rate of TFP. In the following, we introduce the setting for estimating the determinants of TFP in order to find sources for its volatility and further explain what output growth depends on the MENA region.

Human capital is assumed to be one of the most important drivers for technological progress. Mankiw, Romer, and Weil (1992) augment the standard Solow model and include human capital as an additional input factor in the production function. They show that a larger share of the variation in output can be explained by accounting for human capital as an input factor of production. We adapt this methodology and include human capital in the production function using a specification suggested by Hall and Jones (1999). Equation [5] shows that human capital is included in the growth decomposition framework as an input factor. Accounting for human capital as a production factor, however, does not imply that human capital is not a driver of productivity at the same time. The well-known contribution from Benhabib and Spiegel (1994) provides a theoretical background for this reasoning. They argue that the level of human 
capital increases the ability of a country to develop technologies domestically and, based on Nelson and Phelps (1966), to adopt new technologies from abroad. Furthermore, they state that the technology growth rate of a country depends on the gap between the technological leader and the country's level of development. The following equation shows this relationship.

$$
\ln A_{i t}-\ln A_{i, t-1}=g\left(H_{i t}\right)+c\left(H_{i t}\right)\left[\frac{\max A_{t}-A_{i t}}{A_{i t}}\right]
$$

where $A_{i t}$ is TFP in country $i$ in year $t$, and $g(\cdot)$ and $c(\cdot)$ are two functions with $\frac{\partial g}{\partial H} \geq 0$ and $\frac{\partial c}{\partial H} \geq 0$. The first term on the right-hand side in eq. [6] measures the extent to which human capital enhances TFP growth via domestic innovations, and the second term captures the catch-up effect with the leading country.

In order to test in a regression framework whether these effects apply to the MENA countries, we estimate the following relationship

$$
\begin{aligned}
\ln A_{i t}= & \alpha+\beta_{1} \ln A_{i, t-1}+\beta_{2} \ln \frac{Y_{i, t-1}}{N_{i, t-1}}+\beta_{3} H_{i, t-1} \\
& +\beta_{4}\left[H_{i, t-1} \frac{Y_{i, t-1}}{N_{i, t-1}}\right]+\mathbf{X}_{\mathbf{i}, \mathbf{t}-\mathbf{1} \gamma+\mu_{i}+v_{t}+\varepsilon_{i t}}
\end{aligned}
$$

where $\mu_{i}$ and $v_{t}$ are country and year specific fixed effects, respectively, $\frac{Y_{i, t-1}}{N_{i, t-1}}$ is lagged GDP per capita, and $\mathbf{X}_{\mathbf{i}, \mathbf{t}-\mathbf{1}}$ an additional set of lagged control variables that vary by specification. In order to reduce possible problems stemming from endogeneity, all explanatory variables enter in lags. ${ }^{3}$ The coefficient of the human capital term, $\beta_{3}$, is expected to be positive whenever the level of human capital in a country enables it to produce domestic innovations that boost productivity. The interaction term of human capital and the level of initial development, approximated by GDP per capita, allows for a nonlinear effect of human capital on productivity. The sign of $\beta_{4}$ is expected to be negative, assuming that countries with initially low levels of development gain more from increases in the human capital stock.

The choice of additional control variables $\mathbf{X}$ is based on the findings of previous studies. Miller and Upadhyay (2000) study the effect of openness and trade orientation on TFP and find that openness increases TFP, if however, trade affects deviations from purchasing power parity the effect on TFP is negative. We use an index of globalization to proxy the outward orientation of a country and interact this variable with a country's human capital. This specification

3 A further discussion of sources of endogeneity, in particular regarding the education variable, is provided in the last paragraph of Section 3.3. 
allows to determine whether globalization increases TFP, conditional on a certain (threshold) endowment of skills/knowledge in an economy.

Danquah, Moral-Benito, and Ouattara (2014) apply a purely data-related approach to estimate the determinants of TFP. Similarly to growth regressions, a number of models can be applied when trying to assess the question of what drives TFP, and the "true" model is a-priori unknown. Different theoretical models suggest different variables to be included in the regression, and it is hardly possible to test for the validity of all the models in one estimation. For this reason, the authors apply the framework of Bayesian Averaging of Classical Estimates (BACE) to gain information about the main determinants of TFP. In the BACE approach, all possible models are estimated to obtain a distribution of the parameters. The effect on TFP attributed to a variable is then a weighted average of the effects that variable has in each single model. The results from Danquah, Moral-Benito, and Ouattara (2014) provide valuable insights, as they highlight the importance of controlling for country-fixed effects that capture country characteristics which do not change over time. Examples for such constant characteristics of a country are geographical or climactic factors, or cultural and institutional environments to the extent that they are persistent. Their findings further accentuate the importance of controlling for the openness of a country and the lagged level of GDP per capita.

\subsection{Data}

The dependent variable, the logarithm of TFP, is based on the growth decomposition discussed in Section 2.2 and in the Appendix. Data on GDP per capita is taken from the World Bank's World Development Indicators. The share of individuals with secondary and tertiary education in the total working-age population (age group 15-64) is obtained from the Barro and Lee (2013) dataset on educational attainment. The IIASA-VID dataset (Lutz et al. 2007) would be preferable, but the coverage of the MENA countries is slightly better in the Barro and Lee (2013) dataset. To measure the dimension of globalization we use the KOF Index of Globalization (Dreher 2006) obtained from the Quality of Governance dataset (Teorell et al. 2011). This index accounts for the three main dimensions of globalization: (i) economic globalization, measured by flows of capital, goods, and services, (ii) political globalization, characterized by the diffusion of government policies and (iii) social globalization, that captures the spread of ideas, information, images, and people (Dreher 2006). Table 4 in the Appendix provides the means and standard deviations of the explained and the explanatory variables by country. 
The various variables describing the business environment of the countries used in Section 4 are taken from the World Development Indicator database, so are the research and development-related variables and the measures that are used as proxies for infrastructure. The Corruption Perception Index (Transparency International) as well as the indices for regulatory quality, political stability and government effectiveness (Kaufmann, Kraay, and Mastruzzi 2009) are taken from the Quality of Governance dataset (Teorell et al. 2011).

The core econometric analysis relies on data for 11 MENA countries, ${ }^{4}$ and covers the period between 1980 and 2009. Several gaps in the data cause the panel to be unbalanced. For Kuwait, data is missing during 1990 and 1994 as well as from 2008 onwards, and due to missing data on gross fixed capital formation, the United Arab Emirates and Yemen are not included before the early 1990s. The specifications that involve the KOF Index of Globalization are restricted to the period 1980-2006. In spite of the gaps, an appropriate number of countries representing the Maghreb, Mashreq, and GCC regions in combination with a sufficient length of the time series allow a robust empirical analysis of the drivers of TFP in the region.

\subsection{Results}

The results of the estimation of different model specifications are displayed in Table 2. All estimations control for country-specific fixed effects and include a full set of time dummy variables. Column (1) shows that the log of TFP is strongly persistent and thus the inclusion of a lag of the dependent variable as a regressor is required. The specification in Column (2) tests for the effect of income convergence in TFP dynamics by including the level of income per capita as an explanatory variable.

The stationarity of TFP indicates that TFP converges within countries, ${ }^{5}$ but the level of income per capita does not appear to be a significant driver of productivity growth in the sample.

In Column (3) human capital is introduced as a potential driver for TFP. Human capital does not have a significant impact on TFP, a result that suggests that domestic innovations are not the driving force of productivity when the whole MENA region is considered. Benhabib and Spiegel (1994) find similar

\footnotetext{
4 Algeria, Bahrain, Egypt, Jordan, Kuwait, Morocco, Saudi Arabia, Syria, Tunisia, UAE and Yemen are included in the sample.

5 When omitting the fixed effects we find that TFP converges across countries as well. The results of this regression are not displayed in this Table.
} 


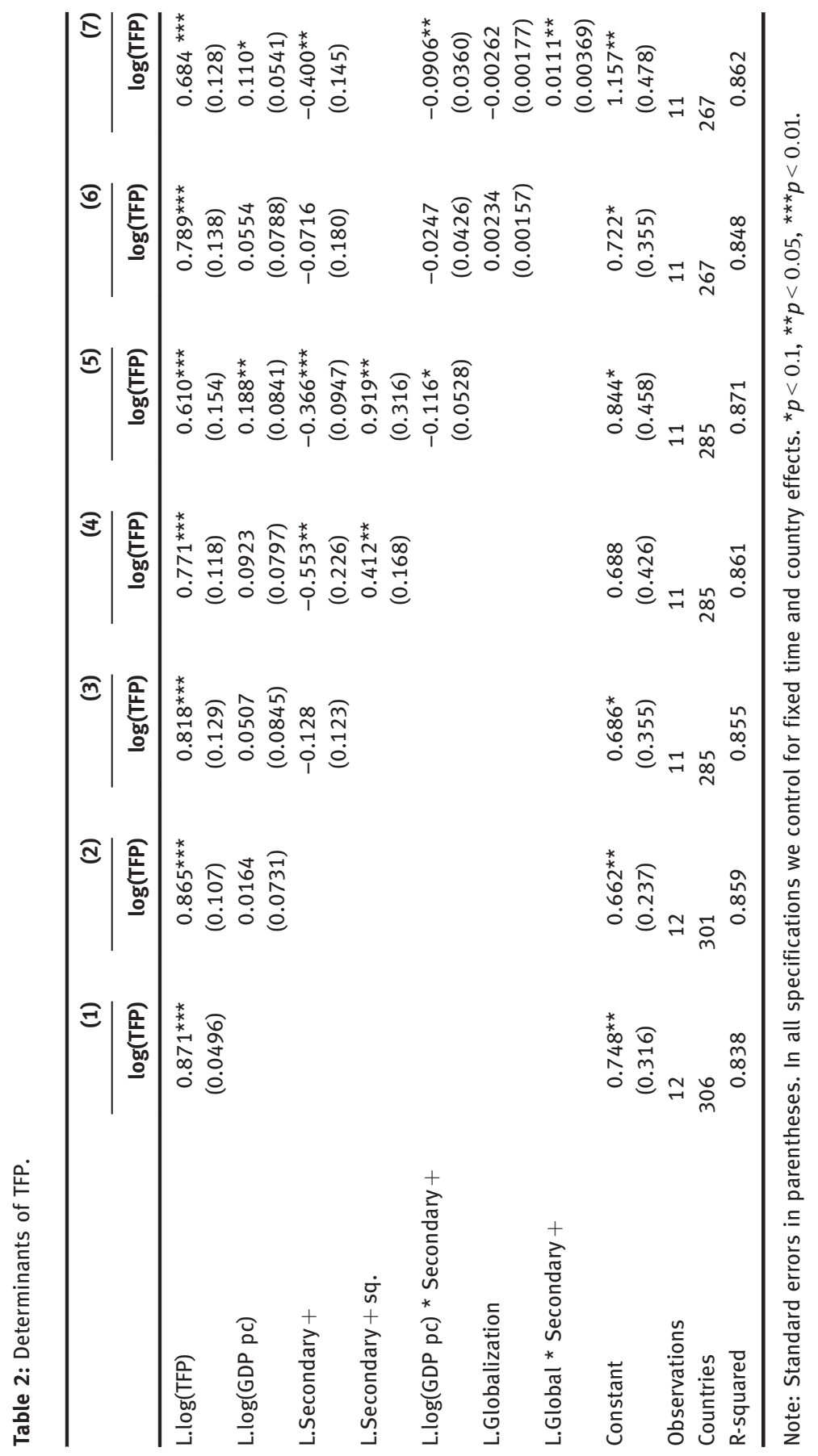


results for low- and middle-income countries. Only in high-income countries are domestic innovations found to provide significant contributions to productivity. They argue that for technologically advanced economies domestic innovation is more effective than technology adoption from abroad. Likewise, less developed countries do not have the prerequisites for effective domestic innovation and it is more efficient for them to adopt existing technologies from abroad. This is further confirmed in Column (4). Allowing for a nonlinear relationship between the share of the working-age population with secondary or tertiary education and TFP shows that only after reaching a certain threshold level of education, its contribution via domestic innovations turns positive. To compute this threshold value, the estimated equation

$$
\ln A_{i t}=\alpha+\beta_{0} \ln A_{i, t-1}+\beta_{1} \ln \frac{Y_{i, t-1}}{N_{i, t-1}}+\beta_{2} H_{i, t-1}+\beta_{3} H_{i, t-1}^{2}+\mu_{i}+v_{t}+\varepsilon_{i t}
$$

is differentiated with respect to $H$. Setting the first derivative to zero allows computing the minimum of the quadratic function, $H^{*}$, i.e. the value of the education level that is theoretically necessary to effectively develop technologies leading to productivity gains,

$$
H^{*}=-\frac{\beta_{2}}{2 \beta_{3}} .
$$

This threshold lies at $67 \%$ of secondary and tertiary education, on average. Figure 4 in the Appendix shows the relationship graphically. How this threshold relates to the countries under consideration is summarized in Table 3. The GCC countries (in our sample: UAE, Bahrain, Kuwait, and Saudi Arabia) show the highest average level of educational attainment in the working-age population

Table 3: Share of working-age population with secondary or tertiary education in 2009.

\begin{tabular}{llll}
\hline $\begin{array}{ll}\text { Relatively low potential } \\
\text { for domestic innovation }\end{array}$ & $\begin{array}{l}\text { Relatively high potential } \\
\text { for domestic innovation }\end{array}$ \\
\hline Yemen & $26 \%$ & & \\
Syria & $29 \%$ & UAE & $69 \%$ \\
Morocco & $34 \%$ & Jordan & $74 \%$ \\
Kuwait & $50 \%$ & Bahrain & $81 \%$ \\
Tunisia & $52 \%$ & & \\
Algeria & $52 \%$ & & \\
Egypt & $63 \%$ & & \\
Saudi Arabia & $64 \%$ & & \\
\hline
\end{tabular}


since the 1980s. However, while Bahrain reached the critical level of education already in the mid-1990s, the UAE did so only during the last few years. Educational attainment in Kuwait is below the level that is necessary to positively contribute to productivity through the channel of domestic innovation in the country. The average educational attainment in the Mashreq region (in our sample: Egypt, Jordan, Syria and Yemen) since the 1980s is clearly below the GCC average; however, the sharp increase in educational attainment in Jordan enables that country to effectively adopt and implement new technologies. Syria and Yemen both exhibit education levels that do not suffice for a positive contribution of domestic innovation on TFP. Concerning the Maghreb region, which is represented by Algeria, Morocco and Tunisia in our sample, our model predicts that the level of human capital in those countries is not high enough to effectively innovate domestically.

The specification in Column (5) includes an interaction term of the level of a country's development (approximated by GDP per capita) and the human capital variable. This allows to test whether human capital speeds up technology adoption (that is, whether countries with relatively low-income levels tend to benefit more from human capital accumulation in terms of technology adoption). The results show that, holding the level of development constant, countries with a higher level of education can adopt technology faster and thus are better able to catch up with leading countries. To put these results differently, countries with low levels of development can benefit from improvements in human capital to a larger extent.

Column (6) relates the level of a country's globalization to its TFP. The insignificant coefficient of the measure of globalization suggests no relationship between technology and a country's TFP growth. When interacting the globalization variable with the human capital variable, it turns out that the effect of the globalization intensity appears to depend positively on the level of human capital (Column 7). Comparing two countries with the same level of human capital, the one with the higher index of globalization is able to adopt more technology from abroad and thus, holding other factors constant, has a higher level of TFP.

Applying the same logic as above when analyzing Column (4), we estimate that whenever the share of the secondary or tertiary educated working-age population exceeds approximately $27 \%$, globalization speeds up the process of technology adoption and thus, increases TFP and finally output growth. Although the threshold number must be interpreted with care as it changes when the model specification is changed, the educational attainment necessary is comparably low and all countries in our sample, with the exception of Yemen, have the required level of human capital to benefit from globalization (see Table 3 for an overview of the educational attainment of the MENA countries). 


\subsubsection{Robustness}

Two forms of robustness checks are performed to validate the results. First, an alternative measure for TFP is used as a dependent variable. Instead of assuming a capital share in income, $\alpha$, of 0.35 , the capital and (human capitalaugmented) labor shares are determined econometrically by estimating a Cobb-Douglas production function under the constraint of constant returns to scale (see eq.[3]) using a panel fixed effects estimator. The resulting capital share in income amounts to 0.332 , as compared to the assumed value of $0.35 .^{6}$ When TFP is calculated based on estimated capital and labor shares, the results of the econometric analysis do not change qualitatively. ${ }^{7}$ A second concern is endogeneity. As a general attempt to reduce possible endogeneity issues, all explanatory variables enter the estimations in the form of lagged values. This procedure might not be sufficient, in particular when the endogeneity of the education variable is concerned. The nature of the education variable reduces the risk of biased coefficients due to simultaneous causality problems, as instead of current enrollment rates, which are likely to be influenced by changes in productivity via (public or private) investment in education, the educational attainment of the labor force is used. Ruling out migration, the educational attainment of the labor force has been determined in the past and is unlikely to be driven by current technological change. ${ }^{8}$ Selective migration, however, could be influenced by changes in TFP and at the same time alter the educational attainment of the labor force. In order to find evidence for biased results stemming for an omission of migration from the empirical analysis, the main results are replicated using migration rates as an additional explanatory variable. ${ }^{9}$ While in some specifications the net migration rates are linked to productivity in a statistically significant way, neither of the results related to the impact of human capital shows a qualitative change. It is important to note that net migration rates are imperfect proxies of education-specific migration rates, and

6 Not imposing the constraint of the capital share plus the labor share being equal to 1 results in an estimated capital share of 0.325 and a human capital-augmented labor share of 0.721 . The null hypothesis of these two coefficients adding up to one cannot be rejected ( $p$-values of 0.456 ).

7 See Edwards (1998) or Miller and Upadhyay (2000) for similar approaches of estimating TFP. 8 At the same time, this variable is a more appropriate approximation of the human capital stock in a country than current enrollment rates.

9 As time series on immigration rates of high-skilled individuals are not available for MENA countries, net migration obtained from the World Development Indicators are used instead. The data is available for all relevant countries for every fifth year and interpolations of the time series, normalized by the size of the population, are used in the regressions. 
this robustness check does not prove that endogeneity is nonexistent. Merely, no evidence for biased coefficient estimates is found. ${ }^{10}$

\section{Correlates of TFP Growth in the Last Decade}

There are several additional factors that are likely to affect a country's productivity level. Technological progress may depend on the business environment of the country (see for example Nicoletti and Scarpetta 2003), its political stability and the quality of its institutions, or the effort that is undertaken by the country's political leadership to enhance technology advancements (see for example Nehru and Dhareshwar 1994; Edwards 1998). In addition, R\&D activities have repeatedly been shown to boost innovations, and as pointed out by Griffith, Redding, and Van Reenen (2004), they enhance a country's ability for technological catch-up. Mc Morrow, Röger, and Turrini (2010) find similar results when analyzing the impact of R\&D on TFP across industries.

Unfortunately, most of these variables cannot be included in the regression analysis, as these factors were not measured for most countries of the MENA region until the early 2000s. In order to get a sense of the correlation of TFP growth with the above measures, average TFP growth rates in the 2000s are plotted against mean values of the variables of interest (Figures 5-7 in the Appendix). Although the econometric analysis in the previous section explains the logarithm of the level of TFP, TFP growth rates are the preferable measure in this setting as they are comparable across countries. Unlike in the regression framework where control variables, in particular the lag of the logarithm of TFP and country-fixed effects, allow an analysis of the effect of changes in the covariates on TFP within countries, thereby establishing comparability, the simplistic scatter plots shown here do not allow for covariates. Thus, the measure of TFP itself is required to be comparable across countries, and a natural candidate is the annual growth rate of TFP.

\subsection{Business Environment and Infrastructure}

The business environment is of particular interest when explaining productivity and technological progress of a country. In the last years, great efforts have been made to quantify business environment-related factors in a way that allows comparison across countries. However, the number of observations is not large

10 The results of the robustness checks are not included in this paper but available upon request. 
enough to estimate the impact on TFP in an econometric model and thus we cannot establish causal relationships. Simple scatter plots that show the correlation between the (post-2000 country means of) TFP growth and the cost of, and the time needed for, starting a new business, and furthermore the World Bank's logistics performance index and the country's road density are displayed in Figure 5 in the Appendix. Countries in which starting a business is relatively cheap and not very time-intensive tend to exhibit higher growth rates of TFP, whereas countries such as Yemen and Djibouti, where business start-ups are both expensive and time-intensive, are associated with lower growth rates of TFP. ${ }^{11}$ The logistics performance index used in the analysis evaluates the trade and transport-related infrastructure (e.g. ports, railroads, roads, information technology). Low values of this index indicate a poor infrastructure, high values a good one. The correlation with TFP growth is slightly positive, although not as strong as for the variables measuring the ease of starting a business. The lower right graph displays a plot of TFP growth against the mean of the road densities and shows a highly positive relationship.

\subsection{Political Stability and Institutions}

Figure 6 displays scatter plots and linear trends that relate TFP growth to political and institutional quality indices, all obtained from the Quality of Governance Dataset (Teorell et al. 2011). The upper-left figure shows the positive relationship of TFP growth and the corruption perception index from Transparency International that assigns higher values to countries in which the perceived extent of corruption is low. The three remaining figures relate institutional characteristics measured by a selection of the World Bank Governance Indicators (Kaufmann, Kraay, and Mastruzzi 2009) to changes in TFP. The scatter plots show that less corruption, better regulatory quality, a higher degree of government effectiveness and a stable political environment are associated with higher growth rates of TFP. As argued by Edwards (1998), better institutions and a sound political environment encourage innovations and promote productive activities.

Further investigation of the scatter plots reveals that the indices themselves are highly positively correlated and countries with high levels of perceived corruption are those exhibiting low regulatory quality, low government

11 As this result does not originate in a causal analysis, it cannot be ruled out that parts of the strong positive correlations observed are driven by third factors that have a positive impact on both TFP growth rates and the business environment, such as political stability, good governance, or a high quality of institutions. 
effectiveness and only limited political stability. Examples are Yemen or Algeria, countries that are placed in the lower left part in each of the graphs, or Bahrain, on the other hand, that is placed in the upper right corner of each graph where data is available.

\subsection{Research and Development}

The last set of graphs, Figure 7, links TFP growth to the share of researchers and technicians working in research and development as well as to the research and development expenditures (as \% of GDP). The relationship between the former two is slightly positive, but mainly driven by the country of Jordan, that has a particularly high share of researchers and technicians. When it comes to research and development expenditures, Morocco and Tunisia invest the highest share of their GDP in R\&D, but they do not reach the TFP growth rates obtained by Kuwait or Jordan.

\section{Conclusions}

Motivated by the findings of a growth decomposition that showed large contributions of TFP growth rates to GDP growth, this piece of research is an effort to estimate the determinants of total factor productivity in the MENA region. Following Benhabib and Spiegel (1994), it is assumed that productivity in a country can be improved either by innovations achieved domestically or by the adoption of foreign technologies. Whereas both require a certain stock of knowledge, the level of human capital needed for technology adoption is lower than for domestic innovations. In the MENA region, a comparably high level of human capital, approximated by the share of people with secondary and tertiary education in the total working-age population, is estimated to be necessary for effective domestic innovations of technology. Bahrain, Jordan, the Emirates and potentially also Saudi Arabia and Egypt appear to possess the stock of human capital required for domestically driven technology improvements. Educational attainment in Yemen, Syria and Morocco, on the other hand, is far below the estimated threshold.

The speed at which countries catch up with the technological leader also depends on each country's level of human capital. The results suggest that holding the level of development constant, countries with a larger stock of human capital converge faster to the technological leader. Increases in the level of human capital in the MENA region thus appear to cause higher TFP, either via 
the channel of domestic innovation or via that of technology adoption. Furthermore, the level of globalization of a country is found to be an important contributor to TFP. As soon as a certain (relatively low) level of knowledge is reached, increases in the extent of globalization positively contribute to TFP.

The relationship of TFP growth rates and the business environment, political stability, institutional quality, and the efforts made to strengthen the research and development sector is assessed by simple scatter plots. Although no conclusions can be drawn about the causal nature of these relationships, the findings suggest that in general, high TFP growth rates are associated with a favorable business environment, stable political conditions, high institutional quality, and appropriate infrastructure.

\section{Appendix}

\section{A Growth Accounting: Data Sources and Construction of Variables}

Due to limited data availability for the countries of interest, some variables used in the growth-accounting exercise have to be approximated or interpolated. In the following, we describe in detail the source of the data, how the different variables have been constructed, and what assumptions are made in the construction process.

We use GDP in constant LCU, obtained from the WDI database. No further modifications are made. Growth rates are computed by taking first differences of the logarithmic values.

The capital stock is constructed by approximating an initial value of the capital stock, ${ }^{12} K_{0}$, and applying the perpetual inventory method for the following periods. In more detail, the following steps were undertaken:

1. Initial capital stock ${ }^{13}$ is approximated by $K_{0}=\frac{I_{0}}{\delta}$, where $I_{\mathrm{o}}$ is the first available data point of Gross Capital Formation (constant LCU) and $\delta$ denotes the depreciation rate. Gross Capital Formation is obtained from the WDI database and a depreciation rate of $\delta=5 \%$ is assumed for all countries.

12 As for most of the countries under consideration, we do not have data on gross capital formation before the 1990s. Setting the initial capital stock to zero, would result in a large upward bias of capital growth rates.

13 The capital stock in $t=0$ can be seen as an accumulation of past depreciated investments. Therefore, $K_{0}=\sum_{s=0}^{S}(1-\delta) I_{0-s}$. For large $S$ this becomes approximately $K_{0}=\frac{1}{\delta} I_{0}$. 
2. Perpetual Inventory: The real capital stock in time $t$ is defined as the depreciated capital stock of time $(\mathrm{t}-1)$ plus the real investments made in time t: $K_{t}=(1-\delta) K_{t-1}+I_{t}$

Total employment (ages 15 and above) is approximated by the labor force retrieved from the WDI database.

Finally, we use the Barro and Lee (2013) dataset for data on educational attainment. They provide mean years of education for every 5 th year. In order to get yearly data, we interpolate the missing values using the following approximation

$$
s_{t}=s_{t-1}\left(\frac{s_{v}}{s_{u}}\right)^{\frac{1}{v-u}}
$$

where $s$ are mean years of schooling, subscripts $\mathrm{u}$ and $\mathrm{v}$ denote two consecutive available values for educational attainment and subscript $t$ the year to be interpolated.

The human capital index $H_{t}$ is the exponential function of average years of education multiplied by average returns to education, $\phi$

$$
H_{t}=\exp \left[\phi s_{t}\right]
$$

Skills-adjusted labor is then simply computed by weighting total employment with the human capital index.
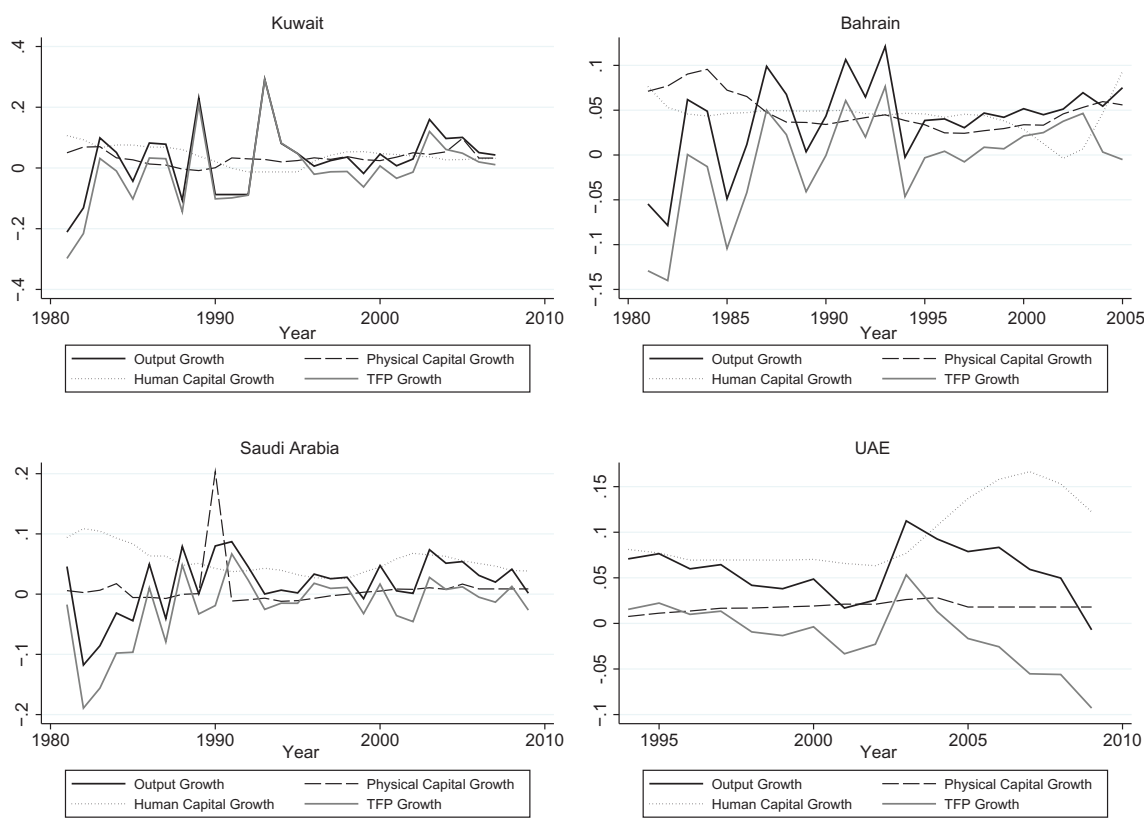

Figure 1: GCC countries: growth decomposition. 

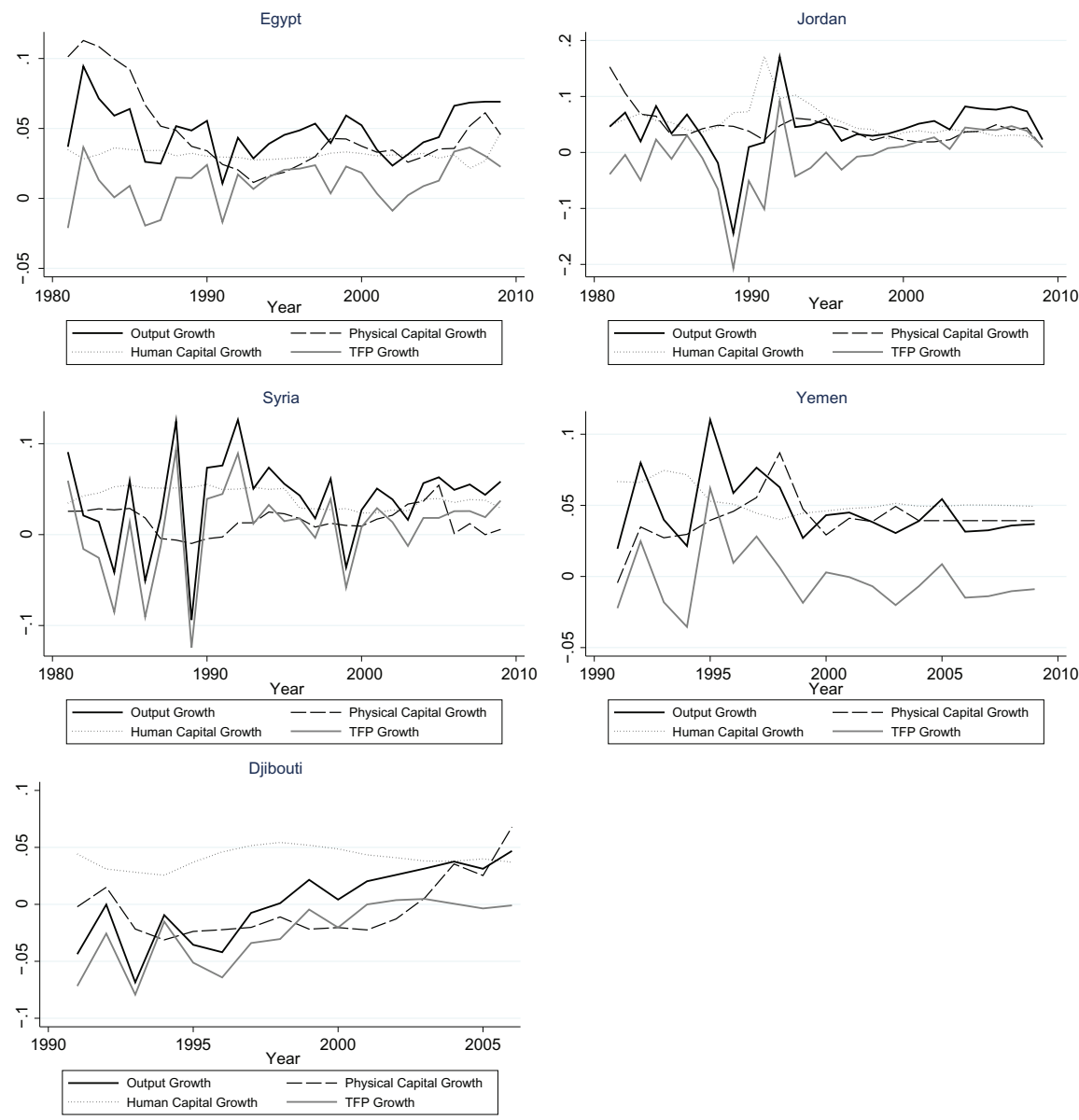

Figure 2: Mashreq countries: growth decomposition. 

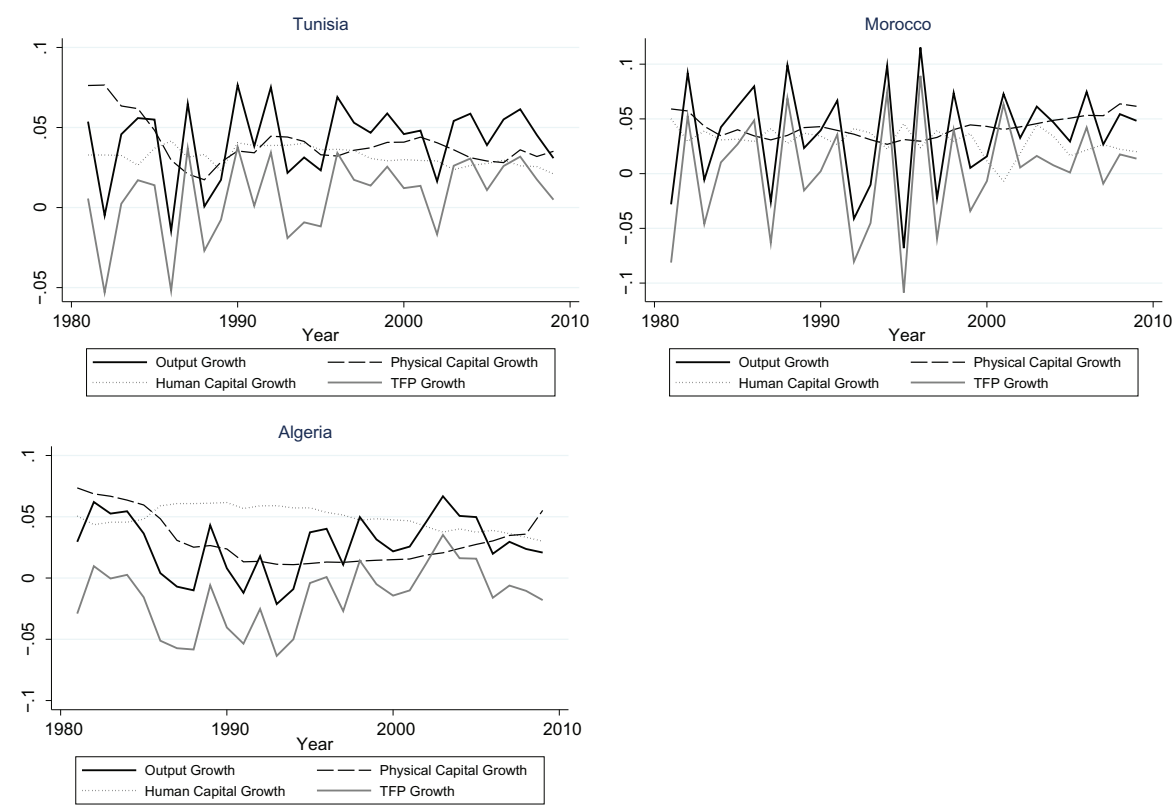

Figure 3: Maghreb countries: growth decomposition.

\section{B Nonlinear Relationship between TFP and Education}

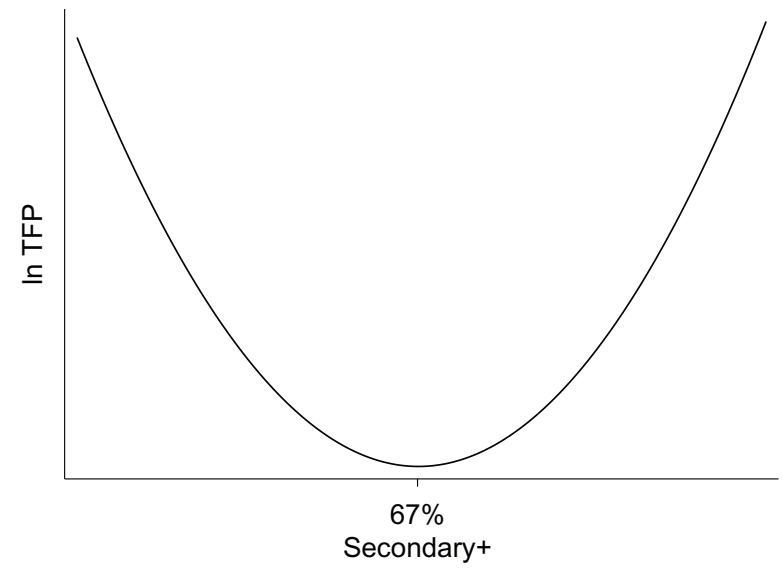

Figure 4: Estimated relationship between $\log$ (TFP) and share of secondary and tertiary educated people at working age. 
C TFP Growth and Business Environment, Institutions and R\&D
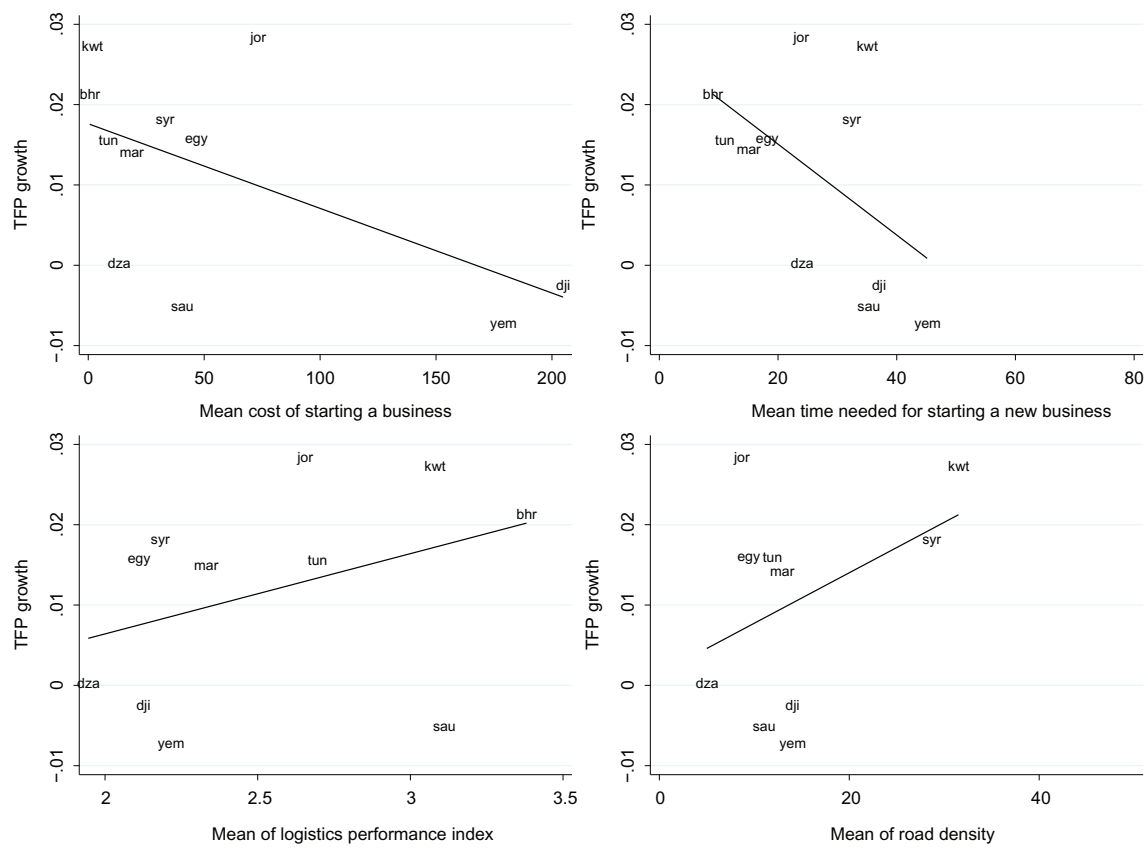

Figure 5: Correlation of business environment-related variables with the post-2000 mean of TFP growth. 

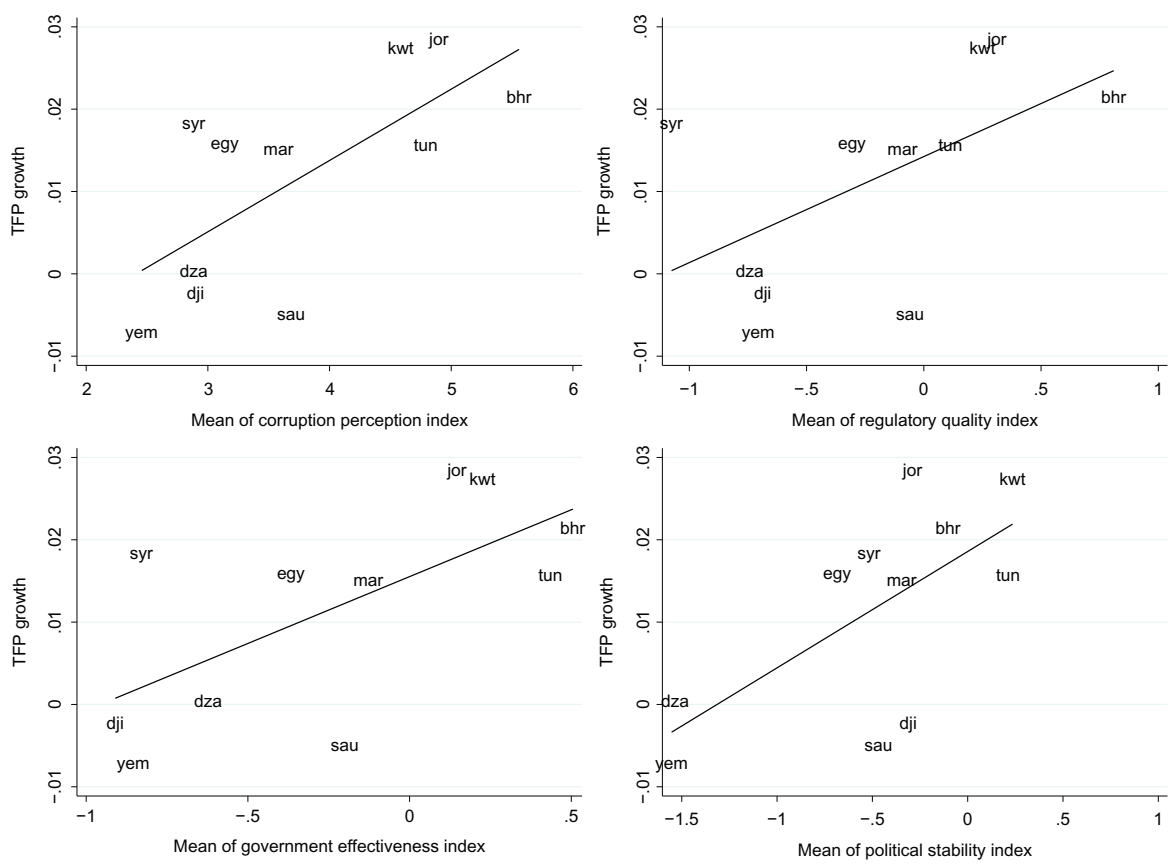

Figure 6: Correlation of political and institutional indices with the post-2000 mean of TFP growth.
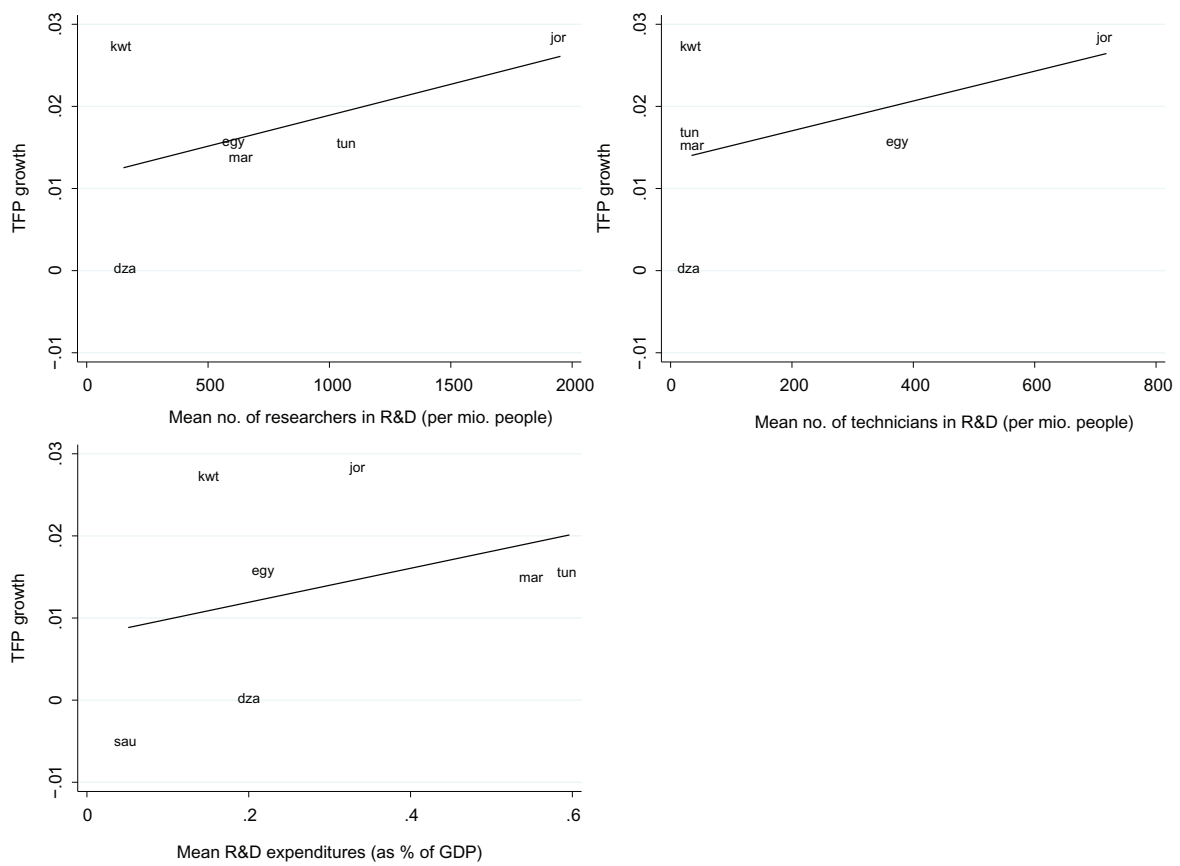

Figure 7: Correlation of R\&D-related variables with the post-2000 mean of TFP growth. 


\section{Summary Statistics}

Table 4: Summary Statistics: Means and standard deviations.

\begin{tabular}{llrrrr}
\hline Country & Stats & $\ln ($ TFP) & In(GDPpC) & Secondary + & Globalization \\
\hline Algeria & Mean & 6.030 & 8.527 & 0.367 & 41.166 \\
& SD & 0.178 & 0.273 & 0.114 & 7.260 \\
Bahrain & Mean & 5.204 & 9.706 & 0.632 & 63.660 \\
& SD & 0.099 & 0.370 & 0.144 & 7.944 \\
Egypt & Mean & 5.313 & 7.952 & 0.428 & 48.708 \\
& SD & 0.099 & 0.466 & 0.135 & 8.172 \\
Jordan & Mean & 4.859 & 8.031 & 0.574 & 59.928 \\
& SD & 0.179 & 0.306 & 0.123 & 9.620 \\
Kuwait & Mean & 5.433 & 10.190 & 0.489 & 62.476 \\
& SD & 0.158 & 0.459 & 0.034 & 4.800 \\
Morocco & Mean & 6.394 & 7.728 & 0.238 & 47.934 \\
& SD & 0.049 & 0.410 & 0.064 & 7.941 \\
Saudi Arabia & Mean & 6.751 & 9.710 & 0.438 & 53.274 \\
& SD & 0.167 & 0.187 & 0.118 & 8.224 \\
Syria & Mean & 7.355 & 7.970 & 0.248 & 40.298 \\
& SD & 0.104 & 0.351 & 0.025 & 4.286 \\
Tunisia & Mean & 4.959 & 8.244 & 0.344 & 55.071 \\
& SD & 0.084 & 0.475 & 0.108 & 5.167 \\
UAE & Mean & 6.818 & 10.601 & 0.541 & 58.151 \\
& SD & 0.067 & 0.137 & 0.127 & 9.747 \\
Yemen & Mean & 6.637 & 7.505 & 0.117 & 33.502 \\
\multirow{2}{*}{ Total } & SD & 0.029 & 0.212 & 0.083 & 6.313 \\
& Mean & 6.023 & 8.713 & 0.401 & 52.771 \\
& SD & 0.900 & 1.043 & 0.183 & 11.827 \\
\hline
\end{tabular}

\section{References}

Baier, S. L., G. P. Dwyer, and R. Tamura. 2006. "How Important Are Capital and Total Factor Productivity for Economic Growth?” Economic Inquiry 44:23-49.

Barro, R. J., and J. W. Lee. 2013. "A New Data Set of Educational Attainment in the World, 1950-2010." Journal of Development Economics 104:184-98.

Benhabib, J., and M. M. Spiegel. 1994. "The Role of Human Capital in Economic Development. Evidence From Aggregate Cross-Country Data." Journal of Monetary Economics 34:143-73. 
Bosworth, B. P., and S. M. Collins. 2003. "The Empirics of Growth: An Update." Brookings Papers on Economic Activity 2003:113-79.

Bosworth, B. P., and S. M. Collins. 2007. Accounting for Growth: Comparing China and India, Working Paper 12943, National Bureau of Economic Research.

Danquah, M., E. Moral-Benito, and B. Ouattara. 2014. "TFP Growth and Its Determinants: A Model Averaging Approach.” Empirical Economics 47:227-51.

Dreher, A. 2006. "Does Globalization Affect Growth? Evidence From a New Index of Globalization.” Applied Economics 38:1091-110.

Edwards, S. 1998. “Openness, Productivity and Growth: What Do We Really Know?" The Economic Journal 108:383-98.

Griffith, R., S. Redding, and J. Van Reenen. 2004. "Mapping the Two Faces of R\&D: Productivity Growth in a Panel of OECD Industries." Review of Economics and Statistics 86:883-95.

Hall, R. E., and C. I. Jones. 1999. "Why Do Some Countries Produce so Much More Output per Worker Than Others?” The Quarterly Journal of Economics 114:83-116.

Kaufmann, D., A. Kraay, and M. Mastruzzi. 2009. Governance Matters VIII: Aggregate and Individual Governance Indicators, 1996-2008, World Bank Policy Research Working Paper No. 4978.

Kneller, R., and P. A. Stevens. 2006. "Frontier Technology and Absorptive Capacity: Evidence From OECD Manufacturing Industries." Oxford Bulletin of Economics and Statistics 68:1-21.

Lutz, W., A. Goujon, S. KC, and W. Sanderson. 2007. "Reconstruction of Population by Age, Sex and Level of Educational Attainment of 120 Countries for 1970-2000." Vienna Yearbook of Population Research 2007:193-235.

Mankiw, N. G., D. Romer, and D. N. Weil. 1992. "A Contribution to the Empirics of Economic Growth." The Quarterly Journal of Economics 107:407-37.

Mc Morrow, K., W. Röger, and A. Turrini. 2010. "Determinants of TFP Growth: A Close Look at Industries Driving the EU-US TFP Gap." Structural Change and Economic Dynamics 21:165-80.

Miller, S. M., and M. P. Upadhyay. 2000. "The Effects of Openness, Trade Orientation, and Human Capital on Total Factor Productivity." Journal of Development Economics 63:399-423.

Nehru, V., and A. Dhareshwar. 1994. New estimates of total factor productivity growth for developing and industrial countries, Policy Research Working Paper Series 1313, The World Bank.

Nelson, R. R., and E. S. Phelps. 1966. "Investment in Humans, Technological Diffusion, and Economic Growth.” The American Economic Review 56:69-75.

Nicoletti, G., and S. Scarpetta. 2003. "Regulation, Productivity and Growth: OECD Evidence." Economic Policy 18:9-72.

Solow, R. M. 1956. "A Contribution to the Theory of Economic Growth.” The Quarterly Journal of Economics 70:65-94.

Teorell, J., N. Charron, M. Samanni, S. Holmberg, and B. Rothstein. 2011. The Quality of Government Dataset, version 6 Apr 11, University of Gothenburg: The Quality of Government Institute.

Vandenbussche, J., P. Aghion, and C. Meghir. 2006. "Growth, Distance to Frontier and Composition of Human Capital." Journal of Economic Growth 11:97-127. 